\title{
Effects of the long-term use of maxillary protraction facemasks with skeletal anchorage on pharyngeal airway dimensions in growing patients with cleft lip and palate
}

\author{
Jung-Eun Kim ${ }^{\mathrm{a}}$ (1) \\ Sunjin Yim ${ }^{b}$ \\ Jin-Young Choic \\ Sukwha Kim ${ }^{\text {d }}$ \\ Su-Jung Kim ${ }^{\mathrm{e}}$ (1) \\ Seung-Hak Baek ${ }^{\mathrm{f}}$ (1)
}

${ }^{a}$ Department of Dentistry, Graduate School, Kyung Hee University, Seoul, Korea

${ }^{\mathrm{b}}$ Department of Dentistry, Graduate School, Seoul National University, Seoul, Korea

'Department of Oral and Maxillofacial Surgery, School of Dentistry, Seoul National University, Seoul, Korea

${ }^{\mathrm{d}}$ Department of Plastic and Reconstructive Surgery, College of Medicine, Seoul National University, Seoul, Korea

'Department of Orthodontics, School of Dentistry, Kyung Hee University,

Seoul, Korea

'Department of Orthodontics, School of Dentistry, Seoul National University, Seoul, Korea

\begin{abstract}
Objective: To investigate the effects of the long-term use of a maxillary protraction facemask with miniplate (FM-MP) on pharyngeal airway dimensions in growing patients with cleft lip and palate (CLP). Methods: The study included 24 boys with CLP (mean age, 12.2 years; mean duration of FM-MP therapy, 4.9 years), divided into two groups according to the amount of A point advancement to the vertical reference plane (VRP): Group 1, $>4 \mathrm{~mm}$; Group 2, $<2 \mathrm{~mm} ; \mathrm{n}=12 /$ group. After evaluating the skeletodental and airway variables using lateral cephalograms acquired before and after FM-MP therapy, statistical analyses were performed. Results: Group 1 showed greater forward and downward displacements of the posterior maxilla (posterior nasal spine [PNS]-horizontal reference plane [HRP]; PNSVRP), greater increase in ANB, more forward tongue position (tongue tip-Pt vertical line to Frankfort horizontal plane), and greater increase in the oropharynx (superior posterior airway space [SPAS]; middle airway space [MAS]) and upper nasopharynx (PNS-adenoid2) than did Group 2. While maxillary advancement (A-VRP and PNS-VRP) correlated with increases in SPAS, MAS, and PNS-adenoid2, downward displacement of the PNS (PNS-HRP) correlated with increases in SPAS, MAS, PNSadenoid1, and PNS-adenoid2, and with a decrease in vertical airway length (VAL). Mandibular forward displacement and decrease in mandibular plane correlated with increases in MAS. Conclusions: FM-MP therapy had positive effects on the oropharyngeal and nasopharyngeal airway spaces without increases in VAL in Group 1 rather than in Group 2. However, further validation using an untreated control group is necessary.
\end{abstract}

[Korean J Orthod 2020;50(4):238-248]

Key words: Growing patients with cleft lip and palate, Maxillary protraction, Facemask with miniplate, Pharyngeal airway dimension

Received October 21, 2019; Revised February 27, 2020; Accepted March 3, 2020.

Corresponding author: Su-Jung Kim.

Professor, Department of Orthodontics, School of Dentistry, Kyung Hee University, 26, Kyungheedae-ro, Dongdaemun-gu, Seoul 02447, Korea.

Tel +82-2-958-9458 e-mail ksj113@khu.ac.kr

Corresponding author: Seung-Hak Baek.

Professor, Department of Orthodontics, School of Dentistry, Seoul National University, 101, Daehak-ro, Jongno-gu, Seoul 03080, Korea.

Tel +82-2-2072-3952 e-mail drwhite@unitel.co.kr

How to cite this article: Kim JE, Yim S, Choi JY, Kim S, Kim SJ, Baek SH. Effects of the long-term use of maxillary protraction facemasks with skeletal anchorage on pharyngeal airway dimensions in growing patients with cleft lip and palate. Korean J Orthod 2020;50:238-248.

(C) 2020 The Korean Association of Orthodontists.

This is an Open Access article distributed under the terms of the Creative Commons Attribution Non-Commercial License (http://creativecommons.org/licenses/by-nc/4.0) which permits unrestricted non-commercial use, distribution, and reproduction in any medium, provided the original work is properly cited. 


\section{INTRODUCTION}

Patients with cleft lip and palate (CLP) have been reported to present impaired craniofacial and upper airway development. ${ }^{1,2}$ They have craniofacial deformities characterized by nasomaxillary deficiency mostly due to the inhibitory effects of scar tissues from primary surgeries. $^{3-5}$ The maxillomandibular skeletal discrepancies relative to the cranium influence the morphology and dimension of the upper airway, which encompasses the nasal cavity and pharyngeal airway spaces. ${ }^{6,7} \mathrm{~A}$ previous study demonstrated that nasal airway patency was significantly lower on the cleft side than on the non-cleft side. ${ }^{8}$ A recent cone-beam computed tomography study also revealed that oropharyngeal airway dimension and volume were significantly reduced in patients with CLP than in age-matched controls without CLP.' Accordingly, patients with CLP are liable to experience respiratory functional disorders like mouth breathing, snoring, and obstructive sleep apnea. ${ }^{9,10}$

As a treatment modality for skeletal modification in preadolescent or adolescent patients with CLP, the maxillary protraction facemask has been commonly supplemented with or without maxillary expansion. The main skeletal and dental effects of the protraction facemask include forward and downward displacements of the maxilla, counterclockwise rotation of the palatal plane, clockwise rotation of the mandible that increases lower facial height, proclination of the upper incisors, retroclination of the lower incisors, and decrease of overbite. ${ }^{11,12}$ A few studies elucidated that short-term application of the facemask increased nasopharyngeal airway dimensions, including increasing airway length, without causing significant changes in oropharyngeal or hypopharyngeal airway spaces in children with Class 111 malocclusion. ${ }^{13-15}$ However, only few studies have reported the effects of the facemask on skeletal and upper airway morphology in patients with CLP by comparing them to controls without CLP. Moreover, the scar tissues affect not only abnormal growth and development but also treatment response and stability, and the treatment effect of maxillary protraction in patients with CLP may differ from that of patients with Class 111 malocclusion without CLP.

Recently, the introduction of skeletal anchorage to maxillary protraction has increased the range of skeletal effects up to post-adolescent age groups with less dentoalveolar effects. ${ }^{16}$ Baek et al. ${ }^{17}$ suggested facemask with miniplate (FM-MP) therapy as an effective option for maxillary deficiency in patients with CLP. Based on the findings of previous studies reporting more favorable skeletodental effects of FM-MP therapy over those of conventional facemask therapy, representing greater maxillary advancement with lesser clockwise rotation of the mandible in adolescent patients with $\mathrm{CLP},{ }^{18,19}$ we anticipated a different influence on the upper airway dimension and morphology. Accordingly, the aim of this retrospective study was to investigate the effects of the long-term use of the FM-MP on pharyngeal airway dimensions in growing patients with CLP who are liable to experience upper airway impairment.

\section{MATERIALS AND METHODS}

\section{Patients}

Seventy-five patients with CLP who underwent FMMP therapy at the Department of Orthodontics, Seoul National University Dental Hospital, were initially recruited. The inclusion criteria were as follows: (1) patients diagnosed with non-syndromic unilateral or bilateral CLP (UCLP or BCLP, respectively); (2) patients treated using an identical surgical technique performed by a single surgeon (Millard rotation and advancement flap for cheiloplasty at 3 to 5 months after birth or Furlow double-opposing Z-plasty for one-stage palatorrhaphy at 12 to 18 months after birth); (3) patients whose miniplates were installed by a single surgeon and who underwent FM-MP therapy for at least or more than 2 years under a single orthodontist; (4) boys in the growth stage with a skeletal maturation index of less than 5 before the start of FM-MP therapy; $;^{20}$ and (5) patients who had skeletal Class 111 relationship with maxillary hypoplasia (SNA $<78^{\circ}$ and ANB $<0^{\circ}$ ). The exclusion criteria were as follows: (1) patients who had craniofacial anomalies; (2) patients who had a history of primary gingivoperiosteoplasty or velopharyngoplasty; (3) patients who were girls, in order to avoid the influence of sex; and (4) patients with A point advancement ranging between $2 \mathrm{~mm}$ and $4 \mathrm{~mm}$. Patients who had more than $4 \mathrm{~mm}$ of A point advancement were included in the experimental group, because this amount of advancement shows a therapeutic effect of one cusp width correction. Since less than $2 \mathrm{~mm}$ of A point advancement might be comparable to natural growth changes in patients with $\mathrm{CLP}^{21}$ these patients were included in the positive control group.

The final study sample comprised 24 boys with CLP (13 with UCLP and 11 with BCLP; mean age, $12.2 \pm$ 2.2 years; mean duration of FM-MP therapy, $4.9 \pm 1.6$ years). They were divided into two groups according to the amount of A point advancement to the vertical reference plane (VRP): Group 1 included 12 boys with advancement $>4 \mathrm{~mm}$, mean age of 11.7 years, and mean duration of FM-MP therapy of 4.9 years; Group 2 included 12 boys with advancement $<2 \mathrm{~mm}$, mean age of 12.1 years, and mean duration of FM-MP therapy of 4.8 years (Table 1). This study was reviewed and approved by the Institutional Review Board of Seoul National Uni- 
Table 1. Demographic data of patients

\begin{tabular}{|c|c|c|c|c|c|}
\hline \multirow[t]{2}{*}{ Variable } & \multicolumn{2}{|c|}{$\begin{array}{c}\text { Group } 1 \\
(\mathrm{n}=12 \text { boys with } \\
6 \mathrm{UCLP} \text { and } 6 \text { BCLP) }\end{array}$} & \multicolumn{2}{|c|}{$\begin{array}{c}\text { Group } 2 \\
\text { ( } n=12 \text { boys with } \\
7 \text { UCLP and } 5 \text { BCLP) }\end{array}$} & \multirow[t]{2}{*}{$p$-value } \\
\hline & Mean & SD & Mean & SD & \\
\hline Age at the T0 stage (yr) & 11.7 & 3.1 & 12.1 & 2.3 & 0.135 \\
\hline Mean duration of FM-MP (yr) & 4.9 & 1.6 & 4.8 & 2.2 & 0.865 \\
\hline
\end{tabular}

Independent $t$-test was performed.

Group 1, A point advancement $>4 \mathrm{~mm}$; Group 2, A point advancement $<2 \mathrm{~mm}$; UCLP, unilateral cleft lip and palate; BCLP, bilateral cleft lip and palate; SD, standard deviation; T0, before treatment; FM-MP, facemask with miniplate.
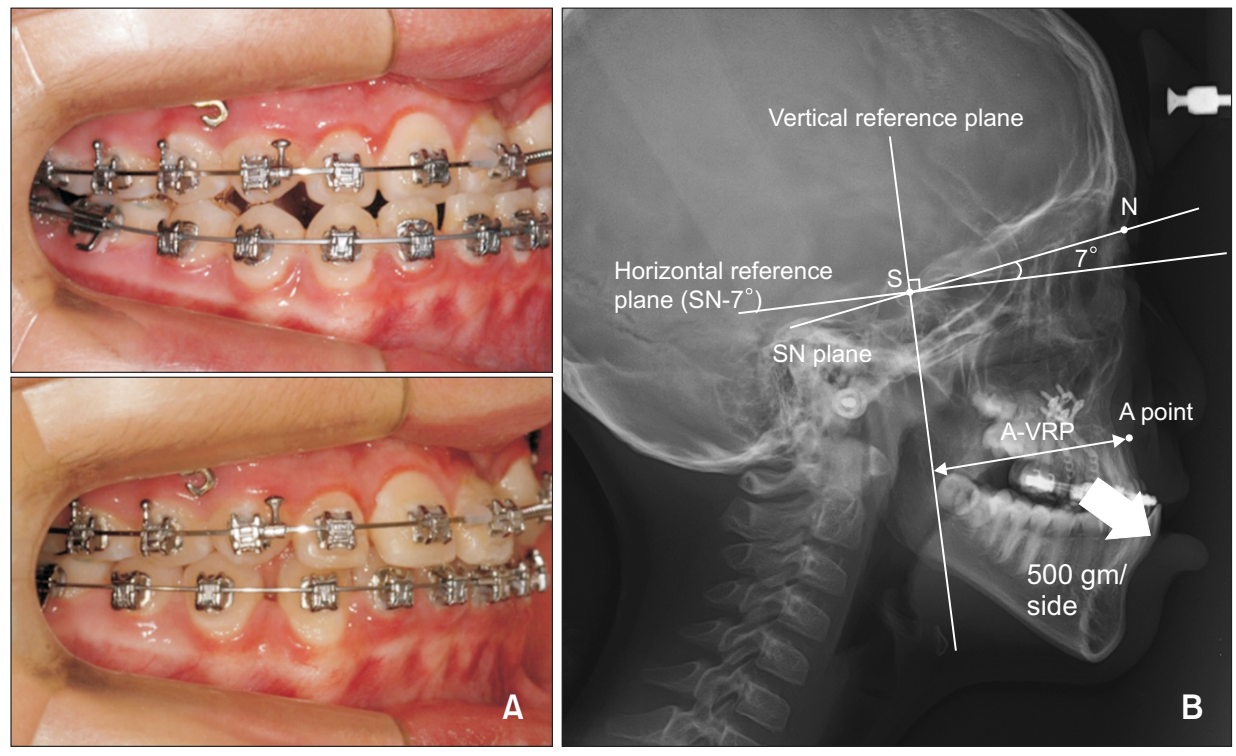

Figure 1. A, An example of facemask with miniplate (FMMP) therapy. B, Reference lines. The horizontal reference plane (HRP) passes the Sella (S) at an angle of 7 degree clockwise to the Sella-Nasion (SN) plane. The vertical reference plane (VRP) is perpendicular to the HRP passing through the S. A-VRP is the horizontal distance from the VRP to A point. versity School of Dentistry (ERI 18019).

\section{Protocol of FM-MP therapy}

The protocol of FM-MP therapy was as follows. ${ }^{17,18}$ After placement of curvilinear surgical miniplates (KLS Martin, Tuttlingen, Germany) on the infrazygomatic crest area ( 1 per side), the ends of the miniplates were exposed through the attached gingiva between the maxillary canine and first premolar. At 8 weeks after the placement of the miniplates, a Petit-type facemask (Kwang Myung DAICOM, Seoul, Korea) was delivered. Patients were instructed to apply the elastics from the miniplates to the facemask hooks for at least 12 to 14 hours per day with $500 \mathrm{~g}$ of force on each side (Figure 1).

\section{Cephalometric analysis}

Lateral cephalograms were assessed before (T0) and at the time of completion of FM-MP therapy (T1). While acquiring the lateral cephalograms, the patients were asked to stand with a natural head position, to occlude slightly after a usual swallow, and to hold their breath after the end of expiration. ${ }^{22}$ The reference planes, land- marks, and cephalometric variables used in this study are shown in Figures 1 and 2, and Table 2. Since the nasion area showed forward growth during FM-MP therapy, the actual sagittal and vertical changes of point $A$ and the posterior nasal spine (PNS) had to be evaluated using the VRP and horizontal reference plane (HRP) passing the Sella point. ${ }^{19}$

A single investigator traced the lateral cephalograms and measured the cephalometric variables using the Vceph software ver. 7.0 (Osstem Implant Co., Seoul, Korea). All variables from randomly selected patients were remeasured by the same operator after a 2-week interval. The intraoperator measurement error was assessed using the intraclass correlation coefficient. Since no significant differences were observed between the first and second measurements, the first set of measurements was used for analysis.

\section{Statistical analysis}

The power analysis was performed to determine the sample size with G*Power version 3.1.9.4 (Kiel University, Kiel, Germany; 0.05 two-sided significance level) using 

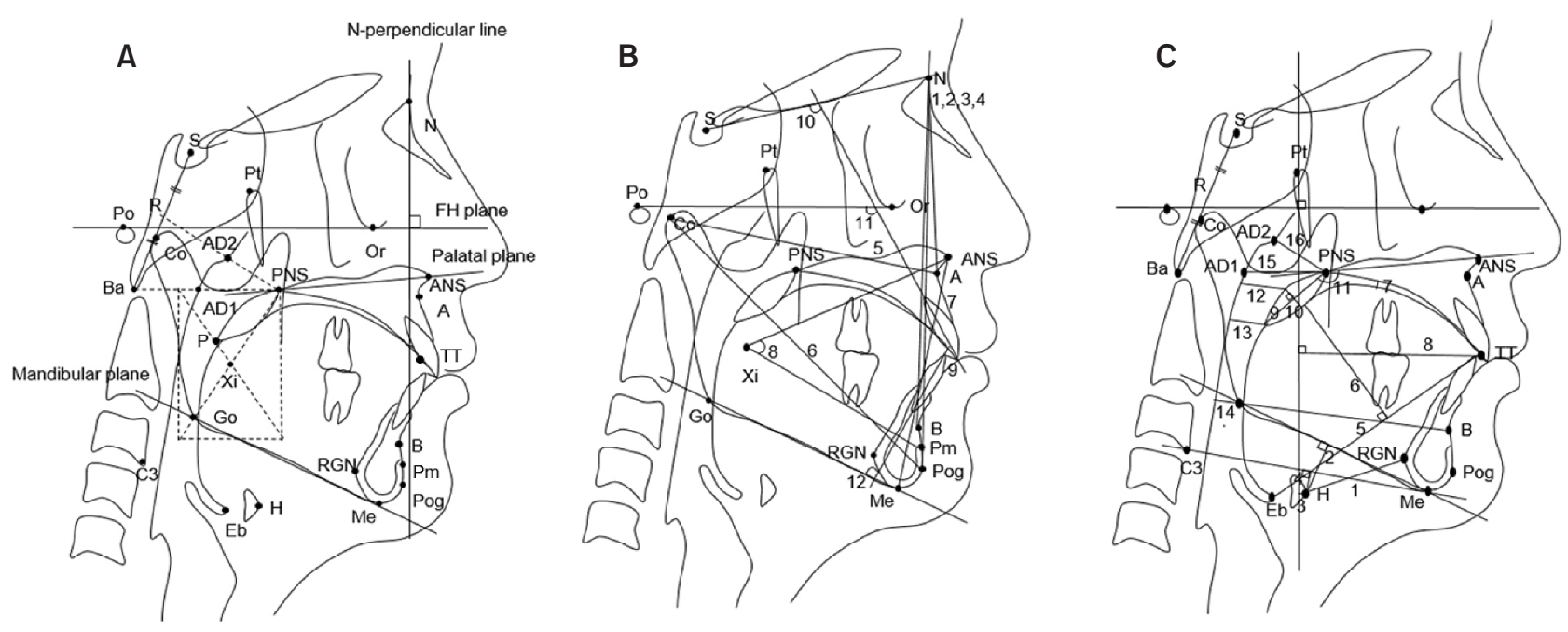

Figure 2. Cephalometric landmarks and measurements. $A$, Landmarks. S, Sella; N, nasion; Ba, basion; Or, orbitale; Po, porion; Pt, pterygoid point; $\mathrm{R}$, midpoint between sella and basion; AD1, adenoid point 1 (adenoid tissue on the PNS-Ba line); AD2, adenoid point 2 (adenoid tissue on the R-PNS line); Co, condylion; Go, gonion; ANS, anterior nasal spine; PNS, posterior nasal spine; $A$, point $A ; B$, point $B$; $T$, tongue tip; Pog, pogonion; Me, menton; $P$, tip of the soft palate; Eb, base of the epiglottic fold; $H$, hyoidale (the most anterosuperior point on the body of the hyoid bone); RGN, retrognathion; $\mathrm{Pm}$, protuberance menti; $\mathrm{Xi}$, geometric center of the ramus; FH, Frankfort horizontal; $\mathrm{C}$, the third vertebrae. B, Skeletodental variables. 1, SNA; 2, SNB; 3, SN-Pog; 4, ANB; 5, effective maxillary length (EMxL); 6, effective mandibular length (EMnL); 7, ANS-Me; 8, lower facial height (ANS-Xi-Pm); 9, overjet; 10, U1-SN; 11, U1-FH; 12, L1-MP. C, Airway-related variables. hyoid bone 1, H-RGN; 2, MP-H; 3, H-PTV; 4, H-C3Me; tongue 5, TGL; 6, TGH; 7, Td-PP; 8, TT-PTV; soft palate 9, SPL; 10, SPT; 11, SPA; pharyngeal airway 12, SPAS; 13, MAS; 14, IAS; 15, PNS-AD1; 16, PNS-AD2.

See Table 2 for definitions of each landmark or measurement.

the mean and standard deviation values of SNA from a previous study. ${ }^{18}$ Since the sample size required for $80 \%$ power for the significance levels of representative cephalometric parameters was more than 10 per group, we selected 12 patients per group to account for potential dropouts.

All data were analyzed using IBM SPSS Statistics for Windows, version 22.0 (IBM Corp., Armonk, NY, USA). Following the Shapiro-Wilk test to assess the normality of data distribution, the paired $t$-test was performed to assess the treatment changes in each group, and the independent $t$-test was performed to compare the treatment changes in each cephalometric variable between the two groups. To identify correlation factors contributing to the treatment changes in pharyngeal airway dimensions, Pearson's correlation analysis was used. The level of significance was established as $p<0.05$.

\section{RESULTS}

\section{Comparison of the demographic data and cephalometric} variables at TO

No significant differences were observed in age, mean duration of FM-MP therapy (Table 1), and skeletodental and airway space variables at T0 between groups 1 and
2 (all $p>0.05$; Table 3).

Evaluation of the change in cephalometric variables during T0-T1 in each group (Table 4)

Group 1 showed advancement of A point (A-VRP, $6.1 \mathrm{~mm}, p<0.01$; SNA, $2.5^{\circ}$ and A-N perp, $2.7 \mathrm{~mm}$, all $p<0.001$ ), downward and forward displacements of the PNS (PNS-HRP, $4.5 \mathrm{~mm}$; PNS-VRP, $4.8 \mathrm{~mm}$, all $p<$ $0.001)$, increase in ANB $\left(3.4^{\circ}, p<0.01\right)$, increase in effective maxillary and mandibular lengths (EMxL, $6.0 \mathrm{~mm}$ and EMnL, $8.8 \mathrm{~mm}$, all $p<0.001)$, increase in overjet (4.3 $\mathrm{mm}, p<0.001)$ and labioversion of the upper incisors (U1-FH, 7.4 and U1-SN, 7.5 , all $p<0.05$ ), increase in tongue length and forward repositioning of the tongue tip (TGL, $12.8 \mathrm{~mm}, p<0.001$; TT-PTV, $5.8 \mathrm{~mm}, p<$ 0.01 ), decrease in soft palate angle (SPA, $-3.8^{\circ}, p<0.01$ ), and increase in the pharyngeal airway spaces (superior posterior airway space [SPAS], $4.9 \mathrm{~mm}, p<0.01$; middle airway space [MAS], $3.6 \mathrm{~mm}, p<0.001$; inferior airway space [IAS], $2.0 \mathrm{~mm}, p<0.05$; and nasopharyngeal airway space [PNS-ad1, $6.0 \mathrm{~mm}$ and PNS-ad2, $7.4 \mathrm{~mm}$ ], all $p<0.001)$.

Group 2 showed advancement of A point (A-VRP, $1.3 \mathrm{~mm}, p<0.01$ ), downward displacement of the PNS (PNS-HRP, $2.9 \mathrm{~mm}, p<0.001$ ), increase in effective 
Table 2. Definition of the cephalometric skeletodental and airway variables

\begin{tabular}{|c|c|c|c|}
\hline \multicolumn{3}{|c|}{ Variable } & \multirow{2}{*}{$\begin{array}{c}\text { Definition } \\
\text { Distance between point A (A) and vertical reference plane (VRP) }\end{array}$} \\
\hline Skeletodental & & A-VRP (mm) & \\
\hline & & SNA $\left({ }^{\circ}\right)$ & The angle between Sella-Nasion (SN) plane and Nasion-A plane \\
\hline & & A-N perp (mm) & The shortest linear distance between A and N-perpendicular line \\
\hline & & PNS-HRP (mm) & $\begin{array}{l}\text { Distance between posterior nasal spine (PNS) and horizontal } \\
\text { reference plane (HRP) }\end{array}$ \\
\hline & & PNS-VRP (mm) & Distance between PNS and VRP \\
\hline & & $\operatorname{SNB}\left({ }^{\circ}\right)$ & The angle between SN plane and Nasion-B plane \\
\hline & & B-N perp (mm) & The shortest linear distance between point B and N-perpendicular line \\
\hline & & SN-Pog $\left({ }^{\circ}\right)$ & The angle between SN plane and Nasion-Pogonion (Pog) plane \\
\hline & & Pog-N perp (mm) & The shortest linear distance between Pog and N-perpendicular line \\
\hline & & $\operatorname{ANB}\left({ }^{\circ}\right)$ & The angle between Nasion-A plane and Nasion-B plane \\
\hline & & $\operatorname{EMxL}(\mathrm{mm})$ & Distance between condylion (Co) and A \\
\hline & & EMnL (mm) & Distance between Co and Pog \\
\hline & & PP-FH $\left({ }^{\circ}\right)$ & The angle between palatal plane and Frankfort horizontal (FH) plane \\
\hline & & $\mathrm{MP}-\mathrm{FH}\left({ }^{\circ}\right)$ & The angle between FH plane and mandibular plane (MP) \\
\hline & & $\operatorname{LFH}\left({ }^{\circ}\right)$ & $\begin{array}{l}\text { The angle between anterior nasal spine (ANS)-geometric center of the } \\
\text { ramus }(\mathrm{Xi}) \text { plane and } \mathrm{Xi} \text {-protuberance menti }(\mathrm{Pm}) \text { plane }\end{array}$ \\
\hline & & Overjet (mm) & $\begin{array}{l}\text { Horizontal distance between incisal edges of maxillary } \\
\text { and mandibular incisors }\end{array}$ \\
\hline & & $\mathrm{U} 1-\mathrm{SN}\left({ }^{\circ}\right)$ & The angle between the SN plane and the axis of upper central incisor \\
\hline & & $\mathrm{U} 1-\mathrm{FH}\left({ }^{\circ}\right)$ & The angle between the FH plane and the axis of upper central incisor \\
\hline & & $\mathrm{L} 1-\mathrm{MP}\left({ }^{\circ}\right)$ & The angle between MP and the axis of lower central incisor \\
\hline \multirow[t]{18}{*}{ Airway space } & Hyoid bone & H-RGN (mm) & Distance between hyoidale $(\mathrm{H})$ and retrognathion (RGN) \\
\hline & & MP-H (mm) & Distance along perpendicular line from $\mathrm{H}$ to $\mathrm{MP}$ \\
\hline & & H-PTV (mm) & $\begin{array}{l}\text { Distance along perpendicular line from } \mathrm{H} \text { to pterygomandibular vertical } \\
\text { plane (PTV) line }\end{array}$ \\
\hline & & $\mathrm{H}-\mathrm{C} 3 \mathrm{Me}(\mathrm{mm})$ & $\begin{array}{l}\text { Distance along perpendicular line from } \mathrm{H} \text { to the third vertebrae (C3)- } \\
\text { Menton (Me) line }\end{array}$ \\
\hline & Tongue & TGL (mm) & $\begin{array}{l}\text { Tongue length (distance between base of the epiglottic fold }[\mathrm{Eb}] \text { and } \\
\text { tongue tip [TT]) }\end{array}$ \\
\hline & & TGH (mm) & $\begin{array}{l}\text { Tongue height (maximum height of line perpendicular to Eb-TT line } \\
\text { at tongue dorsum) }\end{array}$ \\
\hline & & Td-PP $(\mathrm{mm})$ & Distance along perpendicular line from tongue dorsum (Td) to palatal plane \\
\hline & & TT-PTV (mm) & Distance along perpendicular line from TT to PTV line \\
\hline & Soft palate & SPL (mm) & Soft palate length (distance between PNS and tip of the soft palate $[\mathrm{P}]$ ) \\
\hline & & $\mathrm{SPT}(\mathrm{mm})$ & $\begin{array}{l}\text { Soft palate thickness (maximum thickness of soft palate measured on } \\
\text { line perpendicular to PNS-P) }\end{array}$ \\
\hline & & $\mathrm{SPA}(\mathrm{mm})$ & Soft palate angle (angle between P-PNS and palatal plane) \\
\hline & & P-PTV $(\mathrm{mm})$ & Distance along perpendicular line from P to PTV line \\
\hline & $\begin{array}{l}\text { Pharyngeal } \\
\text { airway }\end{array}$ & SPAS (mm) & $\begin{array}{l}\text { Superior posterior airway space (width of airway behind soft palate along } \\
\text { line parallel to gonion [Go]-B plane) }\end{array}$ \\
\hline & & MAS (mm) & Middle airway space (width of airway along line parallel to Go-B line through P) \\
\hline & & IAS (mm) & Inferior airway space (width of airway along Go-B line) \\
\hline & & $\operatorname{VAL}(\mathrm{mm})$ & Vertical airway length (distance between PNS and Eb) \\
\hline & & PNS-ad1 (mm) & $\begin{array}{l}\text { The distance between PNS and Ad1 (the point where PNS-Basion [Ba] line } \\
\text { intersects the posterior pharyngeal wall) }\end{array}$ \\
\hline & & PNS-ad2 (mm) & $\begin{array}{l}\text { The distance between PNS and Ad2 (the point where a line perpendicular to } \\
\text { Sella [S]-Ba plane passing through PNS intersects the posterior pharyngeal wall) }\end{array}$ \\
\hline
\end{tabular}


Table 3. Comparison of the cephalometric variables between groups 1 and 2 at T0

\begin{tabular}{|c|c|c|c|c|c|c|c|}
\hline \multicolumn{3}{|c|}{ Variable } & \multicolumn{2}{|c|}{ Group 1} & \multicolumn{2}{|c|}{ Group 2} & \multirow{2}{*}{$p$-value } \\
\hline & vartadie & & Mean & SD & Mean & SD & \\
\hline \multirow[t]{18}{*}{ Skeletodental } & & $\mathrm{A}-\mathrm{VRP}(\mathrm{mm})$ & 56.61 & 3.51 & 60.00 & 5.47 & 0.123 \\
\hline & & SNA $\left({ }^{\circ}\right)$ & 74.18 & 2.79 & 73.53 & 3.46 & 0.618 \\
\hline & & A-N perp (mm) & -3.62 & 3.11 & -2.25 & 3.27 & 0.305 \\
\hline & & $\operatorname{SNB}\left({ }^{\circ}\right)$ & 75.48 & 2.84 & 73.42 & 2.74 & 0.084 \\
\hline & & $\mathrm{B}-\mathrm{N}$ perp $(\mathrm{mm})$ & -3.31 & 4.23 & -4.03 & 2.78 & 0.629 \\
\hline & & SN-Pog $\left({ }^{\circ}\right)$ & 75.55 & 2.71 & 73.56 & 2.86 & 0.094 \\
\hline & & Pog-N perp (mm) & -3.36 & 4.62 & -3.56 & 3.18 & 0.903 \\
\hline & & ANB $\left({ }^{\circ}\right)$ & -1.29 & 2.89 & 0.12 & 4.09 & 0.160 \\
\hline & & $\operatorname{EMxL}(\mathrm{mm})$ & 79.17 & 4.53 & 80.03 & 7.06 & 0.726 \\
\hline & & $\mathrm{EMnL}(\mathrm{mm})$ & 108.27 & 6.07 & 106.04 & 8.13 & 0.455 \\
\hline & & PP-FH $\left({ }^{\circ}\right)$ & 0.15 & 2.40 & -0.95 & 1.45 & 0.188 \\
\hline & & MP-FH $\left(^{\circ}\right)$ & 28.09 & 4.52 & 27.67 & 4.71 & 0.823 \\
\hline & & ANS-Me (mm) & 69.72 & 5.90 & 72.79 & 6.42 & 0.235 \\
\hline & & LFH $\left(^{\circ}\right)$ & 49.72 & 4.34 & 52.70 & 4.71 & 0.121 \\
\hline & & Overjet (mm) & -2.75 & 2.39 & -2.90 & 3.04 & 0.893 \\
\hline & & U1-SN $\left({ }^{\circ}\right)$ & 97.63 & 6.32 & 93.74 & 9.19 & 0.240 \\
\hline & & $\mathrm{U} 1-\mathrm{FH}\left({ }^{\circ}\right)$ & 112.04 & 8.07 & 107.06 & 8.40 & 0.152 \\
\hline & & L1-MP $\left({ }^{\circ}\right)$ & 87.02 & 4.51 & 92.04 & 8.61 & 0.087 \\
\hline \multirow[t]{17}{*}{ Airway space } & Hyoid bone & H-RGN (mm) & 34.67 & 5.90 & 38.85 & 5.00 & 0.078 \\
\hline & & MP-H (mm) & 14.10 & 6.38 & 13.98 & 5.52 & 0.963 \\
\hline & & H-PTV (mm) & 0.21 & 5.78 & -3.27 & 6.61 & 0.184 \\
\hline & & $\mathrm{H}-\mathrm{C} 3 \mathrm{Me}(\mathrm{mm})$ & 1.41 & 3.91 & 0.11 & 4.28 & 0.128 \\
\hline & Tongue & TGL (mm) & 68.15 & 6.35 & 74.34 & 8.61 & 0.057 \\
\hline & & TGH (mm) & 31.72 & 4.32 & 31.72 & 4.11 & 0.887 \\
\hline & & Td-PP (mm) & 8.08 & 4.20 & 11.47 & 3.80 & 0.128 \\
\hline & & TT-PTV (mm) & 46.18 & 4.29 & 48.29 & 3.95 & 0.225 \\
\hline & Soft palate & $\mathrm{SPL}(\mathrm{mm})$ & 32.61 & 3.50 & 36.40 & 5.78 & 0.065 \\
\hline & & $\mathrm{SPT}(\mathrm{mm})$ & 8.28 & 1.16 & 9.50 & 2.20 & 0.104 \\
\hline & & $\operatorname{SPA}\left({ }^{\circ}\right)$ & 142.05 & 4.76 & 140.58 & 6.60 & 0.539 \\
\hline & Pharyngeal airway & SPAS (mm) & 13.81 & 3.42 & 13.84 & 2.76 & 0.983 \\
\hline & & MAS (mm) & 13.11 & 2.77 & 11.89 & 3.40 & 0.551 \\
\hline & & IAS (mm) & 12.40 & 3.43 & 12.49 & 2.88 & 0.945 \\
\hline & & VAL (mm) & 63.73 & 4.90 & 67.71 & 8.16 & 0.219 \\
\hline & & PNS-adl (mm) & 22.73 & 3.81 & 23.26 & 4.91 & 0.770 \\
\hline & & PNS-ad2 (mm) & 17.99 & 2.61 & 19.10 & 2.81 & 0.330 \\
\hline
\end{tabular}

Independent $t$-test was performed.

Group 1, A point advancement $>4 \mathrm{~mm}$; Group 2, A point advancement $<2 \mathrm{~mm}$; SD, standard deviation.

See Table 2 for definitions of each landmark or measurement.

maxillary and mandibular lengths (EMxL, $2.6 \mathrm{~mm}$ and EMnL, $8.3 \mathrm{~mm}$, all $p<0.01$ ), increase in labioversion of the upper incisors (U1-FH, 7.2 ${ }^{\circ}, p<0.05$; U1-SN, 7.4 ${ }^{\circ}$, $p<0.01)$, and increase in the pharyngeal airway spaces (SPAS, $2.3 \mathrm{~mm}, p<0.001$; MAS, $1.9 \mathrm{~mm}, p<0.01$; PNS-ad1, $4.4 \mathrm{~mm}$ and PNS-ad2, $4.2 \mathrm{~mm}$, all $p<0.001$ ). 
Table 4. Comparison of the treatment changes in skeletodental and airway variables between groups 1 and 2 (T1-T0)

\begin{tabular}{|c|c|c|c|c|c|c|c|c|c|}
\hline \multirow{2}{*}{\multicolumn{3}{|c|}{ Variable }} & \multicolumn{3}{|c|}{ Group 1} & \multicolumn{3}{|c|}{ Group 2} & \multirow{2}{*}{$p$-value $^{*}$} \\
\hline & & & Mean & SD & $p$-value ${ }^{\dagger}$ & Mean & SD & $p$-value ${ }^{\dagger}$ & \\
\hline \multirow[t]{19}{*}{ Skeletodental } & & $\Delta \mathrm{A}-\mathrm{VRP}(\mathrm{mm})$ & 6.07 & 1.77 & $0.002^{* *}$ & 1.29 & 0.85 & $0.001^{* *}$ & $0.000^{* * *}$ \\
\hline & & $\triangle \mathrm{SNA}\left({ }^{\circ}\right)$ & 2.53 & 1.22 & $0.000^{* * *}$ & 0.54 & 0.75 & 0.330 & $0.000^{* * *}$ \\
\hline & & $\Delta \mathrm{A}-\mathrm{N} \operatorname{perp}(\mathrm{mm})$ & 2.70 & 1.14 & $0.000^{* * *}$ & 1.04 & 0.92 & 0.874 & $0.000^{* * *}$ \\
\hline & & $\triangle \mathrm{PNS}-\mathrm{HRP}(\mathrm{mm})$ & 4.52 & 1.79 & $0.000^{* * *}$ & 2.86 & 1.72 & $0.000^{* * *}$ & $0.030^{*}$ \\
\hline & & $\triangle \mathrm{PNS}-\mathrm{VRP}(\mathrm{mm})$ & 4.76 & 0.82 & $0.000^{* * *}$ & 1.14 & 0.80 & 0.070 & $0.000^{* * *}$ \\
\hline & & $\triangle \mathrm{SNB}\left({ }^{\circ}\right)$ & 0.18 & 2.13 & 0.771 & 0.64 & 2.35 & 0.365 & 0.377 \\
\hline & & $\Delta \mathrm{B}-\mathrm{N}$ perp $(\mathrm{mm})$ & 1.31 & 2.23 & 0.067 & 1.62 & 2.79 & 0.070 & 0.767 \\
\hline & & $\Delta \mathrm{SN}-\mathrm{Pog}\left({ }^{\circ}\right)$ & 0.37 & 2.34 & 0.598 & 0.13 & 2.39 & 0.860 & 0.805 \\
\hline & & $\Delta$ Pog-N perp $(\mathrm{mm})$ & 0.31 & 2.35 & 0.660 & 1.42 & 2.91 & 0.119 & 0.313 \\
\hline & & $\triangle \mathrm{ANB}\left({ }^{\circ}\right)$ & 3.35 & 2.09 & $0.003^{* *}$ & 1.18 & 2.21 & 0.090 & $0.008^{* *}$ \\
\hline & & $\Delta \mathrm{EMxL}(\mathrm{mm})$ & 5.97 & 2.81 & $0.000^{* * *}$ & 2.59 & 1.59 & $0.002^{* *}$ & $0.014^{*}$ \\
\hline & & $\Delta \mathrm{EMnL}(\mathrm{mm})$ & 8.80 & 5.62 & $0.000^{* * *}$ & 8.32 & 5.72 & $0.002^{* *}$ & 0.590 \\
\hline & & $\Delta \mathrm{PP}-\mathrm{FH}\left(^{\circ}\right)$ & -0.70 & 0.77 & 0.109 & 0.22 & 0.79 & 0.364 & 0.143 \\
\hline & & $\Delta \mathrm{MP}-\mathrm{FH}\left({ }^{\circ}\right)$ & -0.62 & 0.96 & 0.300 & 0.14 & 2.34 & 0.838 & 0.597 \\
\hline & & $\Delta \mathrm{LFH}\left({ }^{\circ}\right)$ & 0.23 & 4.07 & 0.851 & 0.63 & 2.79 & 0.448 & 0.777 \\
\hline & & $\Delta$ Overjet $(\mathrm{mm})$ & 4.32 & 2.87 & $0.000^{* * *}$ & 2.83 & 1.53 & 0.110 & 0.662 \\
\hline & & $\Delta \mathrm{U} 1-\mathrm{SN}\left(^{\circ}\right)$ & 7.54 & 8.53 & $0.011^{*}$ & 7.44 & 8.16 & $0.009^{* *}$ & 0.977 \\
\hline & & $\Delta \mathrm{U} 1-\mathrm{FH}\left(^{\circ}\right)$ & 7.43 & 8.52 & $0.012^{*}$ & 7.19 & 8.12 & $0.011^{*}$ & 0.944 \\
\hline & & $\Delta \mathrm{L} 1-\mathrm{MP}\left({ }^{\circ}\right)$ & -1.54 & 6.05 & 0.762 & -2.74 & 4.49 & 0.215 & 0.155 \\
\hline \multirow[t]{17}{*}{ Airway space } & Hyoid bone & $\Delta \mathrm{H}-\mathrm{RGN}(\mathrm{mm})$ & 2.71 & 4.94 & $0.038^{*}$ & 0.67 & 4.86 & 0.644 & 0.112 \\
\hline & & $\Delta \mathrm{MP}-\mathrm{H}(\mathrm{mm})$ & 0.55 & 4.00 & 0.430 & 0.74 & 3.55 & 0.483 & 0.897 \\
\hline & & $\Delta \mathrm{H}-\mathrm{PTV}(\mathrm{mm})$ & 1.01 & 6.29 & 0.347 & 2.02 & 3.13 & $0.047^{*}$ & 0.052 \\
\hline & & $\Delta \mathrm{H}-\mathrm{C} 3 \mathrm{Me}(\mathrm{mm})$ & 0.26 & 3.03 & 0.769 & 0.96 & 2.76 & 0.252 & 0.560 \\
\hline & Tongue & $\Delta \mathrm{TGL}(\mathrm{mm})$ & 12.80 & 5.22 & $0.000^{* * *}$ & 3.54 & 5.15 & 0.137 & $0.000^{* * *}$ \\
\hline & & $\Delta \mathrm{TGH}(\mathrm{mm})$ & 2.44 & 3.02 & 0.317 & 2.09 & 3.82 & 0.085 & 0.803 \\
\hline & & $\Delta \mathrm{Td}-\mathrm{PP}(\mathrm{mm})$ & 0.44 & 2.42 & 0.538 & 0.57 & 3.01 & 0.527 & 0.374 \\
\hline & & $\Delta$ TT-PTV $(\mathrm{mm})$ & 5.79 & 3.36 & $0.002^{* *}$ & 2.03 & 2.92 & 0.245 & $0.001^{* *}$ \\
\hline & Soft palate & $\Delta \mathrm{SPL}(\mathrm{mm})$ & 1.56 & 3.44 & 0.145 & -0.85 & 2.10 & 0.192 & 0.051 \\
\hline & & $\Delta \mathrm{SPT}(\mathrm{mm})$ & 0.39 & 2.08 & 0.532 & 0.52 & 1.81 & 0.340 & 0.869 \\
\hline & & $\Delta \mathrm{SPA}\left(^{\circ}\right)$ & -3.81 & 2.76 & $0.002^{* *}$ & -2.23 & 3.32 & 0.340 & 0.219 \\
\hline & Pharyngeal airway & $\Delta$ SPAS (mm) & 4.92 & 3.01 & $0.002^{* *}$ & 2.25 & 1.19 & $0.000^{* * * *}$ & $0.002^{* *}$ \\
\hline & & $\triangle \mathrm{MAS}(\mathrm{mm})$ & 3.63 & 2.31 & $0.000^{* * *}$ & 1.86 & 1.76 & $0.004^{* *}$ & $0.046^{*}$ \\
\hline & & $\Delta \mathrm{IAS}(\mathrm{mm})$ & 2.00 & 2.72 & $0.027^{*}$ & 0.29 & 3.58 & 0.786 & 0.200 \\
\hline & & $\triangle \mathrm{VAL}(\mathrm{mm})$ & 8.87 & 2.83 & $0.000^{* * *}$ & 7.13 & 5.23 & $0.001^{* *}$ & 0.326 \\
\hline & & $\Delta$ PNS-adl (mm) & 5.96 & 2.29 & $0.000^{* * *}$ & 4.43 & 1.26 & $0.000^{* * *}$ & 0.056 \\
\hline & & $\Delta$ PNS-ad2 (mm) & 7.41 & 1.73 & $0.000^{* * *}$ & 4.23 & 1.36 & $0.000^{* * *}$ & $0.000^{* * *}$ \\
\hline
\end{tabular}

Group 1, A point advancement $>4 \mathrm{~mm}$; Group 2, A point advancement $<2 \mathrm{~mm}$; SD, standard deviation.

See Table 2 for definitions of each landmark or measurement.

${ }^{*} p<0.05,{ }^{* *} p<0.01,{ }^{* * *} p<0.001$.

${ }^{\dagger}$ Paired $t$-test was performed.

${ }^{*}$ Independent $t$-test was performed. 


\section{Comparison of the changes in cephalometric variables between groups 1 and 2 (Table 4)}

Group 1 exhibited greater advancement of the anterior maxilla (A-VRP, $p<0.001$ ), greater amount of forward and downward displacements of the posterior maxilla (PNS-VRP, $p<0.001$; PNS-HRP, $p<0.05$, respectively), greater increase in ANB angle $(p<0.01)$, greater forward tongue position (TT-PTV, $p<0.01$ ) with longer tongue length (TGL, $p<0.001)$, greater increase in SPAS ( $p<$ $0.01)$, MAS $(p<0.05)$, and upper nasopharyngeal space (PNS-ad2, $p<0.001$ ) than did Group 2.

In contrast, no significant differences were observed in the amount of changes in the anteroposterior position of the mandible (SNB, B-N perp, SN-Pog, and Pog$\mathrm{N}$ perp), effective mandibular length (EMnL), palatal plane angle (PP-FH), mandibular plane angle (MP-FH), lower facial height, inclination of the upper and lower incisors (U1-FH, U1-SN, and L1-MP), sagittal and vertical positions of the hyoid bone (H-RGN, MP-H, H-PTV, and $\mathrm{H}-\mathrm{C} 3 \mathrm{Me}$ ), shape and inclination of the soft palate (SPL, SPT, and SPA), IAS, and vertical airway length (VAL) between groups 1 and 2 (all $p>0.05$ ).

\section{Correlation between skeletodental and upper airway variables (Table 5)}

The results of the correlation analysis between skeletodental variables and airway-related variables are presented in Table 5. The airway-related variables that correlated with the amount of maxillary advancement (A-VRP and PNS-VRP) were the increase in upper nasopharyngeal area (PNS-ad2, $R=0.67, p<0.01$ ), upper oropharyngeal area (SPAS, $R=0.57, p<0.01$ ), and lower oropharyngeal area (MAS, $R=0.48, p<0.05$ ), in relation to the increase in tongue length (TGL, $R=0.54$, $p<0.01$ ) and forward tongue position (TT-PTV, $R=0.57$, $p<0.01)$. In addition, downward displacement of the PNS correlated with an increase in lower nasopharyngeal area (PNS-ad1, $R=0.41, p<0.05$ ) and a decrease in $\operatorname{VAL}(R=-0.56, p<0.01)$. Mandibular forward displacement correlated with an increase in PNS-ad $1(R=0.45, p$ $<0.05)$ and MAS $(R=0.46, p<0.05)$, and the decrease in mandibular plane angle correlated with a decrease in MAS $(R=-0.47, p<0.05)$, as well as the upward (MPH, $R=0.59, p<0.01)$ and forward (H-PTV, $R=-0.44, p<$ $0.05)$ displacements of the hyoid bone.

lnversely in terms of pharyngeal changes, skeletal variables correlated with an increase in upper nasopharyngeal variables (PNS-ad2) including the amount of anterior and posterior maxillary protraction. The increase in lower nasopharyngeal variables (PNS-ad1) correlated with the advancement of the posterior maxilla and forward displacement of the mandible. The increase in upper oropharyngeal variables (SPAS) correlated with the downward displacement of the posterior maxilla as well as advancement of the maxilla. The increase in lower oropharyngeal variables (MAS) correlated with maxillary advancement, mandibular forward displacement, and decrease in mandibular plane angle. Neither skeletal nor dental variables showed any correlations with hypopharyngeal airway (IAS) changes.

\section{DISCUSSION}

FM-MP therapy has several advantages over the conventional tooth-borne anchored facemask therapy. First, the facemask appliance is independent of tooth

Table 5. Correlation between the skeletodental and airway-related variables

\begin{tabular}{|c|c|c|c|c|c|c|c|c|c|c|c|c|}
\hline & & & \multicolumn{5}{|c|}{ Pharyngeal airway } & \multicolumn{3}{|c|}{ Hyoid } & \multicolumn{2}{|c|}{ Tongue } \\
\hline \multicolumn{3}{|c|}{ Variable } & $\begin{array}{c}\text { PNS- } \\
\text { ad2 } \\
(\mathbf{m m})\end{array}$ & $\begin{array}{c}\text { PNS- } \\
\text { adl } \\
(\mathrm{mm})\end{array}$ & $\begin{array}{l}\text { SPAS } \\
(\mathrm{mm})\end{array}$ & $\begin{array}{l}\text { MAS } \\
(\mathbf{m m})\end{array}$ & $\begin{array}{l}\text { VAL } \\
(\mathbf{m m})\end{array}$ & $\begin{array}{l}\text { MPH } \\
(\mathbf{m m})\end{array}$ & $\begin{array}{c}\text { H-PTV } \\
\text { (mm) }\end{array}$ & $\begin{array}{c}\text { H-C3Me } \\
\text { (mm) }\end{array}$ & $\begin{array}{c}\text { TGL } \\
(\mathbf{m m})\end{array}$ & $\begin{array}{c}\text { TT-PTV } \\
\text { (mm) }\end{array}$ \\
\hline \multirow{5}{*}{ Maxilla } & A point & $\mathrm{A}-\mathrm{VRP}(\mathrm{mm})$ & $0.667^{* *}$ & 0.297 & $0.569 * *$ & $0.476^{*}$ & 0.159 & -0.047 & -0.101 & -0.042 & $0.544^{* *}$ & $0.573^{* *}$ \\
\hline & & $\operatorname{SNA}\left({ }^{\circ}\right)$ & $0.518^{* *}$ & 0.282 & $0.591^{* *}$ & $0.550^{* *}$ & 0.194 & -0.103 & -0.253 & -0.070 & $0.545^{* *}$ & $0.488^{*}$ \\
\hline & & $\mathrm{EMxL}(\mathrm{mm})$ & 0.219 & 0.357 & $0.680^{* *}$ & $0.452^{*}$ & $0.478^{*}$ & 0.002 & -0.147 & -0.028 & $0.550^{* *}$ & $0.625^{* *}$ \\
\hline & PNS & PNS-HRP (mm) & $0.461^{*}$ & $0.408^{*}$ & $0.551^{* *}$ & $0.470^{*}$ & $-0.559^{* *}$ & -0.028 & -0.070 & -0.068 & $0.579^{* *}$ & $0.568^{* *}$ \\
\hline & & PNS-VRP (mm) & $0.654^{* *}$ & 0.342 & $0.510^{*}$ & 0.397 & 0.118 & -0.142 & -0.046 & -0.176 & $0.546^{* *}$ & $0.652^{* *}$ \\
\hline \multirow[t]{4}{*}{ Mandible } & & $\operatorname{SNB}\left({ }^{\circ}\right)$ & $0.414^{*}$ & $0.421^{*}$ & 0.276 & $0.435^{*}$ & -0.166 & -0.294 & 0.284 & $-0.417^{*}$ & -0.022 & -0.021 \\
\hline & & SN-Pog $\left(^{\circ}\right)$ & 0.226 & $0.449^{*}$ & 0.278 & $0.463^{*}$ & -0.109 & -0.322 & 0.226 & $-0.439^{*}$ & -0.006 & -0.030 \\
\hline & & EMnL (mm) & 0.015 & 0.247 & 0.309 & 0.363 & $0.441^{*}$ & 0.073 & -0.091 & -0.115 & 0.396 & $0.446^{*}$ \\
\hline & & $\mathrm{MP}-\mathrm{FH}\left({ }^{\circ}\right)$ & -0.292 & -0.349 & -0.318 & $-0.466^{*}$ & 0.038 & $0.585^{* *}$ & $-0.436^{*}$ & 0.361 & 0.216 & -0.083 \\
\hline
\end{tabular}

Pearson's correlation analysis was performed.

See Table 2 for definitions of each landmark or measurement.

${ }^{*} p<0.05,{ }^{* *} p<0.01$. 
movement resulting from fixed orthodontic treatment. Second, the FM-MP can apply more orthopedic force directly to the circummaxillary sutures. Third, fixed orthodontic treatment can be performed simultaneously in the maxillary arch during maxillary protraction. Therefore, the increase in ANB caused by FM-MP therapy and labioversion of the maxillary incisor during decrowding caused by the fixed appliance (Table 4) could occur simultaneously, as confirmed by previous studies. ${ }^{17-19}$

This study elucidated the effect of the long-term application of bone-anchored maxillary protraction throughout adolescence on pharyngeal airway development in operated patients with CLP. The most clinically relevant finding of our study was that the FM-MP resulted in significant therapeutic outcomes representing extensive levels of pharyngeal enlargement from the nasopharynx to lower oropharynx, with no increase in total upper airway length in relation to FM-MP-dependent differences in skeletal changes even in patients with CLP.

As for the maxillary skeletal effects of FM-MP therapy in patients with CLP, the mean advancements of the anterior maxilla (A point) were significantly greater in Group 1 than in Group $2(p<0.001)$. When we evaluated the maxillary skeletal effects on the posterior maxillary area (PNS), it revealed lesser amount of advancement than did the anterior maxilla with downward displacement; however, no significant counterclockwise rotation of the palatal plane occurred thereafter. The orthopedic effect of FM-MP therapy on the posterior maxillary area, where the pharyngeal airway muscles are attached, was exclusively focused on in our study that also investigated the underlying mechanism of pharyngeal airway enlargement. Forward and downward displacements of the PNS resulting from the therapeutic acceleration by the FM-MP in addition to natural growth might contribute to significant enlargement of nasopharyngeal airway dimensions behind the posterior maxilla.

More interestingly, the FM-MP resulted in not only nasopharyngeal (PNS-ad2) but also oropharyngeal airway enlargement (SPAS and MAS), with no changes in the hypopharyngeal space (IAS) and total upper airway length (VAL), which is different from the effect of the conventional facemask reported in previous studies. ${ }^{23}$ The possible mechanisms underlying the opening of larger levels of pharyngeal airway spaces when using the FM-MP are as follows. First, with advancement of the anterior maxilla, forward repositioning of the tongue and increase in tongue length could be accompanied by an increase in the oropharyngeal spaces behind the tongue base, which corresponded to the finding of a previous study. ${ }^{24}$ Second, the therapeutic effect of the FM-MP on the mandible could not be clearly identified from the growth change in this study because of the large interindividual variations; nonetheless, the mandibular plane was slightly decreased even with 6.13 -fold greater maxillary advancement. Considering that clockwise rotation of the mandible occurs with conventional maxillary protraction treatment, which may induce pharyngeal narrowing ${ }^{25}$ and that patients with CLP have a more vertical growth pattern than do patients without $\mathrm{CLP}^{26}$ the achievement of a well-controlled vertical dimension with sufficient maxillary protraction can be a great benefit of FM-MP therapy in patients with a risk of airway impairment. Third, mandibular growth throughout adolescence might advance the tongue position and open the oropharyngeal airway, and accordingly, the increase in MAS could be correlated with mandibular advancement (SNB and SN-Pog). Lastly, forward and upward displacements of the hyoid bone concomitant with mandibular advancement without an increase in the mandibular plane might contribute to oropharyngeal opening (MAS).

Noticeably, the treatment response of the soft palate to the FM-MP was not significant in our CLP population, different from what was observed in previous studies investigating the effect of the conventional facemask on the soft palate and pharyngeal morphology. ${ }^{13,27}$ The soft palate, which is attached to the posterior maxilla and communicates with the tongue via the palatoglossus muscles, ${ }^{27}$ plays an important role in regulating oropharyngeal patency. Accordingly, the soft palate as well as the tongue or hyoid are important therapeutic targets of craniofacial orthopedic reconstruction, especially when targeting airway development. Although palatal surgery seems to have little effect on oropharyngeal development in operated patients with CLP in spite of the anatomic relationship to the soft palate, ${ }^{28}$ an abnormal soft palate with velopharyngeal insufficiency or a history of velopharyngeal surgery in patients with CLP may reduce the responsiveness of the soft palate to protraction treatment of the posterior maxilla. Owing to a possibility of poor response to maxillary protraction treatment in terms of the forward movement of the posterior maxilla in patients with velopharyngeal insufficiency treated using pharyngeal flap surgery, examining the history of velopharyngeal surgery in patients with CLP is important. Soft palate variables indicating the shape and inclination to the palatal plane showed no significant intergroup differences and no correlation with either skeletal changes or pharyngeal airway changes in our study. Nonetheless, FM-MP therapy could improve the pharyngeal dimension in growing patients with CLP.

Controversies still exist regarding the initiation time and total treatment duration of maxillary skeletal protraction. Moreover, no evidence shows that patients with repaired CLP have strongly resistant scar tissue affecting 
the treatment outcome and stability. In terms of early intervention for maxillary growth modification, the optimal patient age is $6-10$ years old when using the conventional facemask. ${ }^{29,30}$ More recently, however, the FMMP has been recommended on the basis of its greater and more favorable skeletal effects over those of the conventional facemask at the age of 10-13 years old to avoid the risks of damaging developing teeth germs in the bone and poor quality of the bone used as a skeletal anchorage. ${ }^{16}$ Despite delayed intervention for maxillary growth modification, the superior skeletal and upper airway effects of the FM-MP over those of the conventional facemask make delayed application a worthy option even in patients with CLP.

The limitations of the present study were as follows. (1) A baseline control group should be established for differentiating the effects of FM-MP therapy from the effects of growth in patients with CLP. Therefore, future studies should aim to include patients with CLP with a similar skeletal pattern and patients not treated using FM-MP therapy (positive control group) to investigate the exclusive effects of FM-MP therapy. (2) Lateral cephalometric assessment of pharyngeal airway dimensions had some fundamental limitations. Nonetheless, lateral cephalometry is the most critical tool for analyzing the relationships between craniofacial skeletal changes and parapharyngeal tissue changes like soft palate, tongue, and hyoid to pharyngeal airway changes. (3) We could not perform any respiratory functional evaluations to support our morphologic findings. Nevertheless, further studies using three-dimensional evaluation in association with respiratory functional analysis could yield more practical information supporting the extended application of the FM-MP in patients with CLP as well as in the non-CLP population with skeletal Class 111 malocclusion. In addition, future studies must investigate the effects of patient compliance to FM-MP therapy, the thickness and density of the cortical bone in the infrazygomatic crest, and the degree and quantity of scar tissue.

\section{CONCLUSION}

Since Group 1 showed more positive effects on the oropharyngeal and nasopharyngeal airway spaces without any increase in VAL than did Group 2, the amount of maxillary protraction with the FM-MP was significantly related with the improvements in these airway spaces. However, further study is necessary to compare the effects of FM-MP therapy on the airway spaces in an untreated CLP control group.

\section{CONFLICTS OF INTEREST}

No potential conflict of interest relevant to this article was reported.

\section{ACKNOWLEDGEMENTS}

This research was supported by a grant of the Korea Health Technology R\&D Project through the Korea Health Industry Development Institute (KHIDI), funded by the Ministry of Health Ct Welfare, Republic of Korea (Grant No. Hl18C1638).

\section{REFERENCES}

1. Celikoglu M, Buyuk SK, Sekerci AE, Ucar Fl, Cantekin K. Three-dimensional evaluation of the pharyngeal airway volumes in patients affected by unilateral cleft lip and palate. Am J Orthod Dentofacial Orthop 2014;145:780-6.

2. Satoh K, Wada T, Tachimura T, Sakoda S, Shiba R. A cephalometric study by multivariate analysis of growth of the bony nasopharynx in patients with clefts and non-cleft controls. J Craniomaxillofac Surg 1998;26:394-9.

3. Jolleys A. A review of the results of operations on cleft palates with reference to maxillary growth and speech function. Br J Plast Surg 1954;7:229-41.

4. Shibasaki Y, Ross RB. Facial growth in children with isolated cleft palate. Cleft Palate J 1969;6:290-302.

5. Hermann NV, Jensen BL, Dahl E, Bolund S, Kreiborg S. A comparison of the craniofacial morphology in 2-month-old unoperated infants with unilateral complete cleft lip and palate, and unilateral incomplete cleft lip. J Craniofac Genet Dev Biol 1999;19:80-93.

6. Karia H, Shrivastav S, Karia AK. Three-dimensional evaluation of the airway spaces in patients with and without cleft lip and palate: a digital volume tomographic study. Am J Orthod Dentofacial Orthop 2017;152:371-81.

7. Akarsu-Guven B, Karakaya J, Ozgur F, Aksu M. Growth-related changes of skeletal and upper-airway features in bilateral cleft lip and palate patients. Am J Orthod Dentofacial Orthop 2015;148:576-86.

8. Kunkel M, Wahlmann U, Wagner W. Nasal airway in cleft-palate patients: acoustic rhinometric data. J Craniomaxillofac Surg 1997;25:270-4.

9. Muntz H, Wilson M, Park A, Smith M, Grimmer JF. Sleep disordered breathing and obstructive sleep apnea in the cleft population. Laryngoscope 2008;118:348-53.

10. Robison JG, Otteson TD. Increased prevalence of obstructive sleep apnea in patients with cleft palate. Arch Otolaryngol Head Neck Surg 2011;137:269-74.

11. Cordasco G, Matarese G, Rustico L, Fastuca S, Caprioglio A, Lindauer SJ, et al. Efficacy of ortho- 
pedic treatment with protraction facemask on skeletal Class 111 malocclusion: a systematic review and meta-analysis. Orthod Craniofac Res 2014;17:13343.

12. Baccetti T, McGill JS, Franchi L, McNamara JA Jr, Tollaro 1. Skeletal effects of early treatment of Class 111 malocclusion with maxillary expansion and facemask therapy. Am J Orthod Dentofacial Orthop 1998;113:333-43.

13. Kaygisiz E, Tuncer BB, Yüksel S, Tuncer C, Yildiz C. Effects of maxillary protraction and fixed appliance therapy on the pharyngeal airway. Angle Orthod 2009;79:660-7.

14. Oktay H, Ulukaya E. Maxillary protraction appliance effect on the size of the upper airway passage. Angle Orthod 2008;78:209-14.

15. Sayinsu K, lsik F, Arun T. Sagittal airway dimensions following maxillary protraction: a pilot study. Eur J Orthod 2006;28:184-9.

16. Cevidanes L, Baccetti T, Franchi L, McNamara JA Jr, De Clerck H. Comparison of two protocols for maxillary protraction: bone anchors versus face mask with rapid maxillary expansion. Angle Orthod 2010;80:799-806.

17. Baek SH, Kim KW, Choi JY. New treatment modality for maxillary hypoplasia in cleft patients. Protraction facemask with miniplate anchorage. Angle Orthod 2010;80:783-91.

18. Ahn HW, Kim KW, Yang IH, Choi JY, Baek SH. Comparison of the effects of maxillary protraction using facemask and miniplate anchorage between unilateral and bilateral cleft lip and palate patients. Angle Orthod 2012;82:935-41.

19. On SW, Baek SH, Choi JY. Effect of long-term use of facemask with miniplate on maxillary protraction in patients with cleft lip and palate. J Craniofac Surg 2018;29:309-14.

20. Fishman LS. Radiographic evaluation of skeletal maturation. A clinically oriented method based on hand-wrist films. Angle Orthod 1982;52:88-112.

21. Zhang Y, Jia H, Fu Z, Huang Y, Wang Z, Guo R, et al. Dentoskeletal effects of facemask therapy in skeletal Class 111 cleft patients with or without bone graft. Am J Orthod Dentofacial Orthop 2018;153:542-9.

22. Li HY, Chen NH, Wang CR, Shu YH, Wang PC. Use of 3-dimensional computed tomography scan to evaluate upper airway patency for patients undergoing sleep-disordered breathing surgery. Otolaryngol Head Neck Surg 2003;129:336-42.

23. Ngan P, Wilmes B, Drescher D, Martin C, Weaver B, Gunel E. Comparison of two maxillary protraction protocols: tooth-borne versus bone-anchored protraction facemask treatment. Prog Orthod 2015; 16:26.

24. Ozbek MM, Memikoglu TU, Gögen H, Lowe AA, Baspinar E. Oropharyngeal airway dimensions and functional-orthopedic treatment in skeletal Class 11 cases. Angle Orthod 1998;68:327-36.

25. Akcam MO, Toygar TU, Wada T. Longitudinal investigation of soft palate and nasopharyngeal airway relations in different rotation types. Angle Orthod 2002;72:521-6.

26. van den Dungen GM, Ongkosuwito EM, Aartman $1 \mathrm{H}$, Prahl-Andersen B. Craniofacial morphology of Dutch patients with bilateral cleft lip and palate and noncleft controls at the age of 15 years. Cleft Palate Craniofac J 2008;45:661-6.

27. Lee JW, Park KH, Kim SH, Park YG, Kim SJ. Correlation between skeletal changes by maxillary protraction and upper airway dimensions. Angle Orthod 2011;81:426-32.

28. Xu Y, Zhao S, Shi J, Wang Y, Shi B, Zheng Q, et al. 3-dimensional computed tomographic analysis of the pharynx in adult patients with unrepaired isolated cleft palate. J Oral Maxillofac Surg 2013;71:1424-34.

29. McNamara JA Jr. An orthopedic approach to the treatment of Class 111 malocclusion in young patients. J Clin Orthod 1987;21:598-608.

30. Kapust AJ, Sinclair PM, Turley PK. Cephalometric effects of face mask/expansion therapy in Class 111 children: a comparison of three age groups. Am J Orthod Dentofacial Orthop 1998;113:204-12. 